\title{
The efficacy of endoscopic therapy for pancreas divisum: a meta-analysis
}

\author{
Lamprinos Michailidis, Bilal Aslam, Alla Grigorian, Houssam Mardini
}

University of Kentucky College of Medicine, USA

\section{Abstract}

\section{Introduction}

It is estimated that $5-10 \%$ of people are born with pancreas divisum (PDiv) [1,2], which has been implicated in the pathogenesis of acute, recurrent and chronic pancreatitis, as

Department of Medicine, Division of Digestive Diseases and Nutrition, University of Kentucky College of Medicine, USA

\section{Conflict of Interest: None}

Correspondence to: Lamprinos Michailidis, MD, Division of Digestive Diseases and Nutrition. University of Kentucky College of Medicine, 800 Rose Street Room MN649, Lexington, KY, 40536, USA, Tel.: +1 832929 5089, Fax: + 1859257 8860,

e-mail: michailidis@uky.edu

Received 24 January 2017; accepted 24 April 2017; published online 12 May 2017

DOI: https://doi.org/10.20524/aog.2017.0159 well as pancreatic type abdominal pain. Ductal obstruction and/or minor papilla stenosis have been proposed as responsible for the clinical presentation [3], which is categorized into 3 groups: recurrent acute pancreatitis (RAP) episodes, chronic pancreatitis (CP) and pancreatic-type pain (PP) with no objective findings of pancreatitis [3-5]. Therefore, dorsal ductal decompression at the level of the minor papilla has been the mainstay of surgical and/or endoscopic therapies of PDiv. Endoscopically, the most frequently employed methods are minor papilla sphincterotomy, minor papilla sphincteroplasty, and dorsal duct stenting alone or in combination with the aforementioned. While these interventions are widely accepted and performed in patients with clinically evident PDiv, most of the evidence available comes from small, uncontrolled, retrospective studies. In addition, efficacy rates are widely variable and the predictors of successful endoscopic therapy remain unclear. We sought to perform a meta-analysis of studies 
to estimate the efficacy of endoscopic therapy and identify potential predictors of successful endoscopic intervention in patients with PDiv by subgroup and meta-regression analysis.

\section{Materials and methods}

Design, analysis, and reporting were performed according to the PRISMA (Preferred Reporting Items for Systematic Reviews and Meta-Analyses) statement and guidelines [6].

\section{Literature search}

A systematic literature search was performed to identify all reports of endoscopic therapy attempts in patients with PDiv through January of 2016. The electronic databases searched included MEDLINE (PubMed), and ScienceDirect (as of January 5, 2016). The key words and terms searched included: ("Pancreas Divisum" OR "Pancreatic Divisum") AND ("Endoscopic therapy" OR "Endotherapy" OR "Endoscopy" OR "ERCP"). The search was performed within the title, abstract, and key words. The references of relevant articles were reviewed and additional abstracts were added. The search strategy is detailed in Fig. 1.

\section{Study selection and inclusion criteria}

Two reviewers (LM \& BA) independently searched the literature and identified studies for inclusion. Disagreements were resolved by consensus between the two authors and discussion with a senior author (HM) when necessary. Exclusion criteria were: article published in language other than English, abstract form only with no full text available, case series with total number of patients less than or equal to 5 , case reports, review articles, and series that including a pediatric patient population or were not relevant to the research question. Studies focusing on a subset of PDiv patients, such as those relating to santorinicele, were excluded [7]. Studies with unconventional interventions, such as botulinum toxin injection [8], were also excluded from the review as they did not fall into the three standard categories of endotherapy. Studies with both complete and incomplete divisum patients were included.

\section{Data extraction and quality assessment}

Data included the following pre-defined characteristics and variables: first author last name, year of publication, study design, patient demographics (mean age, sex), number of patients with each clinical presentation (RAP versus $C P$ versus $\mathrm{PP}$ ), number of patients who only received endotherapy, type of endotherapy used, follow-up duration, definition of successful endotherapy, total success rates, success rates for each clinical presentation, rates of adverse events and rates of pancreatitis following endoscopic retrograde cholangiopancreatography (ERCP). Since all studies identified were case series, the quality of each study was assessed using the checklist developed by Moga et al (Institute of Health Economics, Alberta, Canada) to assess the quality of case series (Table 2A) [9]. The number of points scored by each study can be seen in Table $2 \mathrm{~B}$. Studies scoring $>14$ points are considered to be of "good" quality.

\section{Heterogeneity testing and publication bias assessment}

Assessment of heterogeneity was performed by calculating Cochran's $Q$ statistic, $\tau^{2}$ (estimates the between-study variance) and $I^{2}$ (quantifies the degree of heterogeneity) with $\mathrm{P}$ values $<0.1$ considered statistically significant $[10,11]$. Publication bias was assessed using a funnel plot. Heterogeneity was

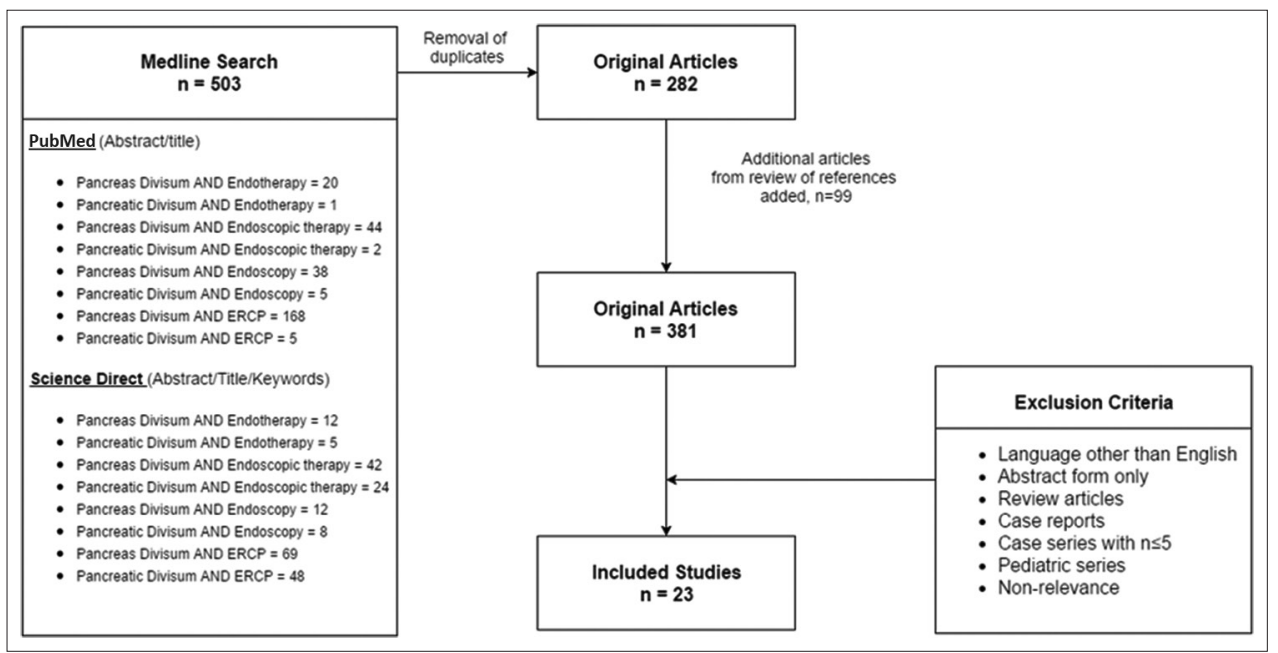

Figure 1 Literature search flowchart

ERCP, endoscopic retrograde cholangiopancreatography 
assessed for each individual outcome (endotherapy success rate, pancreatitis rate) and subgroup (Total, RAP, CP, PP).

\section{Outcomes measured}

1. Author-defined overall success rates of endotherapy, as well as success rates for each individual clinical presentation: RAP, CP, PP

2. Overall reported post-ERCP pancreatitis rates

3. Patient population-related and study design-related potential predictors of successful endotherapy

\section{Data synthesis and statistical analysis}

Only the patients for whom final outcomes were reported were included in the analysis. Patients who were lost to follow up were not included. Separate pooled success rates for each of the clinical presentations (RAP, CP, PP) were calculated by analyzing 3 different subgroups. Post-ERCP pancreatitis rates were pooled and analyzed for the studies that reported them. Variables of interest were treated as continuous variables with means and variations. A random effects model was used to calculate pooled effects for each outcome and subgroup [12]. Finally, we performed a meta-regression analysis in an attempt to identify predictors of successful endotherapy. The regression model included the following covariates: year of publication, sex, age, mean study follow up in months and type of endoscopic therapy used. We divided the endotherapy into 4 main types: minor papilla sphincterotomy and stent, minor papilla sphincteroplasty and stent, stenting of the minor papilla only (stent only), and combination therapy (combination). The minor papilla sphincterotomy and stenting group was used the reference group, as this is currently the most commonly employed therapy. Several studies reported median ages and/or median durations of follow up; for these studies, means and variances were recalculated using a formula previously described by Hozo et al [13] and mean values were included in the analysis. Six studies [14-19] were not included in the meta-regression because they lacked data for some covariates, bringing the number of studies analyzed to 17. Statistical analyses were performed using Comprehensive Meta-Analysis (CMA) software, version 3.3.070, 2014 (Biostat, Englewood, NJ 07631, USA).

\section{Results}

\section{Descriptive assessment of included studies}

Our initial literature search of online databases yielded 503 articles. After removal of duplicates, 282 articles were selected and further reviewed; 99 original articles were added from crossreferencing, bringing the total number of articles reviewed to 381. Of these, 23 studies were selected for final inclusion after application of the exclusion criteria. The search strategy and study selection process is detailed in Supplemental Fig. 1. Studies included were published during the period from 1988 to 2014. Most studies were retrospective case series conducted at a single center; one study was performed at two centers [15]. Only 5 of the 23 studies were prospective [15,20-23] and only 2 of these included a comparative arm [21,22]. Three were performed in Europe [22,24,25], 3 in Asia [15,26,27], 1 in Australia [28], and the remainder in the United States. Twenty-one of the 23 studies reported adverse events rates. Seventeen of the 23 reported male: female ratios, and $45.4 \%$ of the patients in those studies were male. Twenty-one studies reported specific data on the subjects' age, either mean or median. After statistical conversion of medians to means [13], the average age of subjects was 45.5 years. Twenty-two studies reported mean or median follow up and, in the same fashion, an average follow up of 36.6 months was calculated. The study characteristics are outlined in Table 1.

\section{Qualitative assessment of included studies}

Five of the 23 studies [16,18,27,29,30] had 13/18 "yes" responses and 2 of 23 [19,23] had 11/18 "yes" responses. The results of the validity testing can be viewed in Table $2 \mathrm{~B}$.

\section{Publication bias}

Publication bias was assessed by generating funnel plots. Visual interpretation of the plot for standard error (Fig. 2) shows that the studies are distributed symmetrically around the combined effect size, with the exception of a few smaller studies that appear to have larger than average effect sizes (rates of successful endotherapy in this case); this probably indicates the presence of publication bias.

\section{Heterogeneity}

Assessment of heterogeneity was performed by calculating Cochran's Q statistic, $\tau^{2}$ and $I^{2}$. Substantial heterogeneity was detected $\left(I^{2} \geq 50 \%\right)$ under the fixed effects model, so we

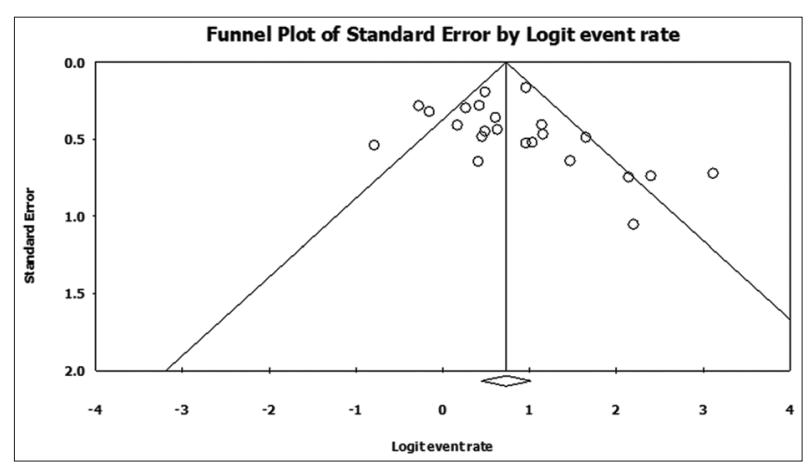

Figure 2 Funnel plot of standard error by logit of successful endotherapy rate 


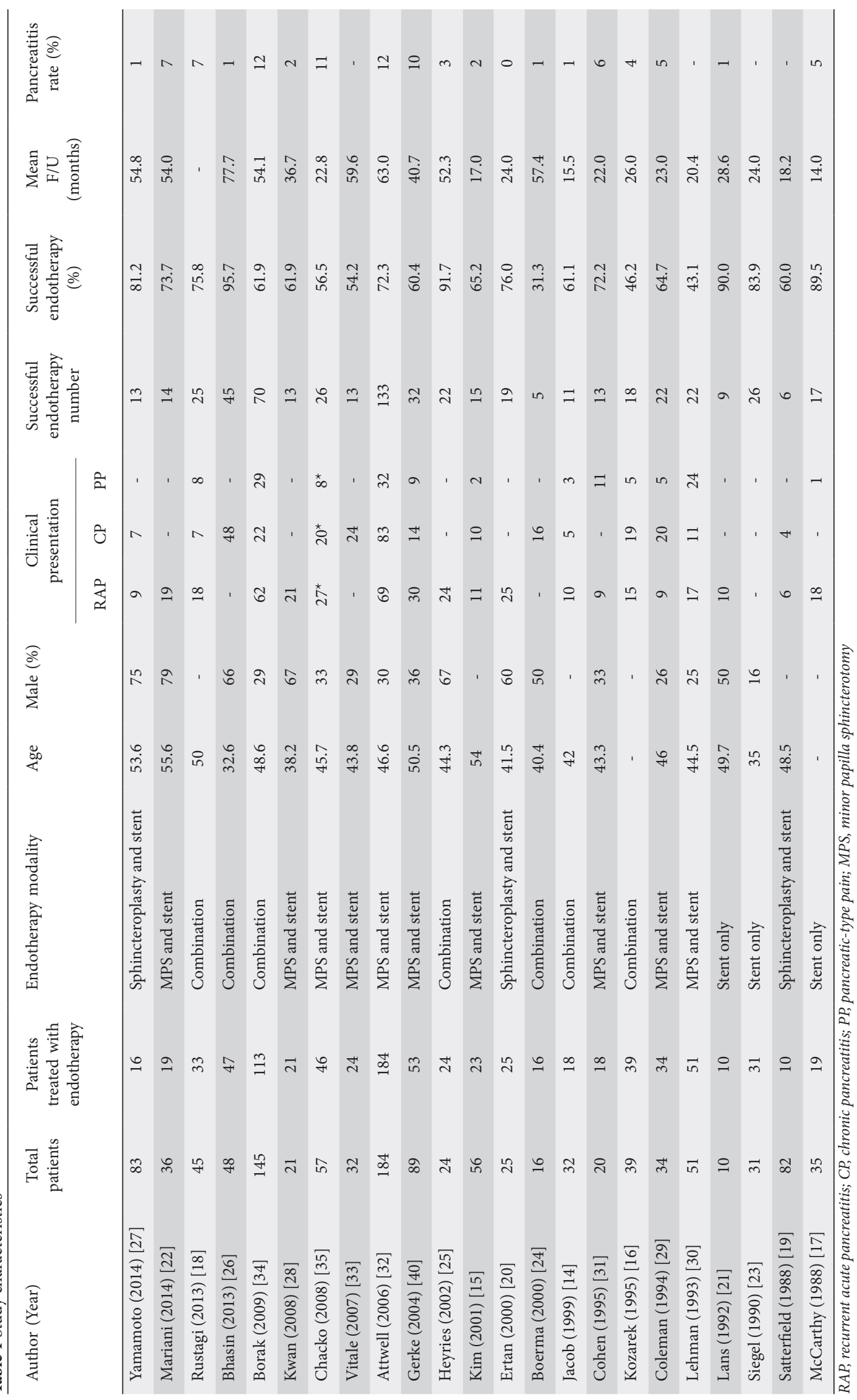


Table 2A Quality assessment tool used [9]

\begin{tabular}{|c|c|}
\hline \multicolumn{2}{|c|}{ Criterion: } \\
\hline 1 & Is the hypothesis/aim/objective of the study stated in the abstract, introduction, or methods section? \\
\hline 2 & Are the characteristics of the patients included in the study clearly described? \\
\hline 3 & Were the case series collected in more than one center? \\
\hline 4 & Are the eligibility criteria (inclusion and exclusion criteria) explicit and appropriate? \\
\hline 5 & Were patients recruited consecutively? \\
\hline 6 & Did patients enter the study at a similar point in the disease? \\
\hline 7 & Did the authors describe the intervention? \\
\hline 8 & In addition to intervention, did the patients receive any co-intervention? \\
\hline 9 & Are outcomes (primary, secondary) clearly defined in the introduction or methodology section? \\
\hline 10 & Did the authors use accurate (standard, valid, reliable) objective methods to measure the outcomes? \\
\hline 11 & Were outcomes assessed before and after intervention? \\
\hline 12 & Were the statistical tests used to assess the primary outcomes appropriate? \\
\hline 13 & Was the length of follow up clearly described/reported? \\
\hline 14 & Was the loss to follow up reported? \\
\hline 15 & $\begin{array}{l}\text { Does the study provide estimates of the random variability in the data for the primary outcomes (e.g. standard error, standard deviation, } \\
\text { confidence intervals)? }\end{array}$ \\
\hline 16 & Are adverse events reported? \\
\hline 17 & Are the conclusions of the study supported by results? \\
\hline 18 & Are both competing interest and source of support for the study reported? \\
\hline
\end{tabular}

Table 2B Quality assessment of studies

\begin{tabular}{|c|c|c|c|c|c|c|c|c|c|c|c|c|c|c|c|c|c|c|c|}
\hline & 1 & 2 & 3 & 4 & 5 & 6 & 7 & 8 & 9 & 10 & 11 & 12 & 13 & 14 & 15 & 16 & 17 & 18 & Sum \\
\hline Yamamoto [27] & $\mathrm{Y}$ & $\mathrm{Y}$ & $\mathrm{N}$ & $\mathrm{Y}$ & $\mathrm{N}$ & $\mathrm{N}$ & $\mathrm{Y}$ & $\mathrm{Y}$ & $\mathrm{Y}$ & $\mathrm{Y}$ & $\mathrm{Y}$ & $\mathrm{Y}$ & $\mathrm{Y}$ & $\mathrm{Y}$ & $\mathrm{N}$ & $\mathrm{Y}$ & $\mathrm{Y}$ & $\mathrm{N}$ & 13 \\
\hline Mariani [22] & $\mathrm{Y}$ & $\mathrm{Y}$ & $\mathrm{N}$ & $\mathrm{Y}$ & $\mathrm{Y}$ & $\mathrm{N}$ & $\mathrm{Y}$ & $\mathrm{Y}$ & $\mathrm{Y}$ & $\mathrm{Y}$ & $\mathrm{Y}$ & $\mathrm{Y}$ & $\mathrm{Y}$ & $\mathrm{Y}$ & $\mathrm{Y}$ & $\mathrm{Y}$ & $\mathrm{Y}$ & $\mathrm{N}$ & 15 \\
\hline Rustagi [18] & $\mathrm{Y}$ & $\mathrm{Y}$ & $\mathrm{N}$ & $\mathrm{Y}$ & $\mathrm{N}$ & $\mathrm{N}$ & $\mathrm{Y}$ & $\mathrm{Y}$ & $\mathrm{Y}$ & $\mathrm{N}$ & $\mathrm{N}$ & $\mathrm{Y}$ & $\mathrm{N}$ & $\mathrm{N}$ & $\mathrm{Y}$ & $\mathrm{Y}$ & $\mathrm{Y}$ & $\mathrm{Y}$ & 11 \\
\hline Bhasin [26] & $\mathrm{Y}$ & $\mathrm{Y}$ & $\mathrm{N}$ & $\mathrm{Y}$ & $\mathrm{N}$ & $\mathrm{N}$ & $\mathrm{Y}$ & $\mathrm{Y}$ & $\mathrm{Y}$ & $\mathrm{Y}$ & $\mathrm{Y}$ & $\mathrm{Y}$ & $\mathrm{Y}$ & $\mathrm{Y}$ & $\mathrm{Y}$ & $\mathrm{Y}$ & $\mathrm{Y}$ & $\mathrm{Y}$ & 15 \\
\hline Borak [34] & $\mathrm{Y}$ & $\mathrm{Y}$ & $\mathrm{N}$ & $\mathrm{Y}$ & $\mathrm{N}$ & $\mathrm{N}$ & $\mathrm{Y}$ & $\mathrm{Y}$ & $\mathrm{Y}$ & $\mathrm{Y}$ & $\mathrm{Y}$ & $\mathrm{Y}$ & $\mathrm{Y}$ & $\mathrm{Y}$ & $\mathrm{Y}$ & $\mathrm{Y}$ & $\mathrm{Y}$ & $\mathrm{N}$ & 14 \\
\hline Kwan [28] & $\mathrm{Y}$ & $\mathrm{Y}$ & $\mathrm{N}$ & $\mathrm{Y}$ & $\mathrm{N}$ & $\mathrm{N}$ & $\mathrm{Y}$ & $\mathrm{Y}$ & $\mathrm{Y}$ & $\mathrm{Y}$ & $\mathrm{Y}$ & $\mathrm{Y}$ & $\mathrm{Y}$ & $\mathrm{Y}$ & $\mathrm{Y}$ & $\mathrm{Y}$ & $\mathrm{Y}$ & $\mathrm{N}$ & 14 \\
\hline Chacko [35] & $\mathrm{Y}$ & $\mathrm{Y}$ & $\mathrm{N}$ & $\mathrm{Y}$ & $\mathrm{Y}$ & $\mathrm{N}$ & $\mathrm{Y}$ & $\mathrm{Y}$ & $\mathrm{Y}$ & $\mathrm{Y}$ & $\mathrm{Y}$ & $\mathrm{Y}$ & $\mathrm{Y}$ & $\mathrm{Y}$ & $\mathrm{Y}$ & $\mathrm{Y}$ & $\mathrm{Y}$ & $\mathrm{Y}$ & 16 \\
\hline Vitale [33] & $\mathrm{Y}$ & $\mathrm{Y}$ & $\mathrm{N}$ & $\mathrm{Y}$ & $\mathrm{N}$ & $\mathrm{N}$ & $\mathrm{Y}$ & $\mathrm{Y}$ & $\mathrm{Y}$ & $\mathrm{Y}$ & $\mathrm{Y}$ & $\mathrm{Y}$ & $\mathrm{Y}$ & $\mathrm{Y}$ & $\mathrm{Y}$ & $\mathrm{Y}$ & $\mathrm{Y}$ & $\mathrm{N}$ & 14 \\
\hline Attwell [32] & $\mathrm{Y}$ & $\mathrm{Y}$ & $\mathrm{N}$ & $\mathrm{Y}$ & $\mathrm{N}$ & $\mathrm{N}$ & $\mathrm{Y}$ & $\mathrm{Y}$ & $\mathrm{Y}$ & $\mathrm{Y}$ & $\mathrm{Y}$ & $\mathrm{Y}$ & $\mathrm{Y}$ & $\mathrm{Y}$ & $\mathrm{Y}$ & $\mathrm{Y}$ & $\mathrm{Y}$ & $\mathrm{Y}$ & 15 \\
\hline Gerke [40] & $\mathrm{Y}$ & $\mathrm{Y}$ & $\mathrm{N}$ & $\mathrm{Y}$ & $\mathrm{N}$ & $\mathrm{N}$ & $\mathrm{Y}$ & $\mathrm{Y}$ & $\mathrm{Y}$ & $\mathrm{Y}$ & $\mathrm{Y}$ & $\mathrm{Y}$ & $\mathrm{Y}$ & $\mathrm{Y}$ & $\mathrm{Y}$ & $\mathrm{Y}$ & $\mathrm{Y}$ & $\mathrm{N}$ & 14 \\
\hline Heyries [25] & $\mathrm{Y}$ & $\mathrm{Y}$ & $\mathrm{N}$ & $\mathrm{Y}$ & $\mathrm{N}$ & $\mathrm{N}$ & $\mathrm{Y}$ & $\mathrm{Y}$ & $\mathrm{Y}$ & $\mathrm{Y}$ & $\mathrm{Y}$ & $\mathrm{Y}$ & $\mathrm{Y}$ & $\mathrm{Y}$ & $\mathrm{Y}$ & $\mathrm{Y}$ & $\mathrm{Y}$ & $\mathrm{N}$ & 14 \\
\hline Kim [15] & $\mathrm{Y}$ & $\mathrm{Y}$ & $\mathrm{Y}$ & $\mathrm{Y}$ & $\mathrm{N}$ & $\mathrm{N}$ & $\mathrm{Y}$ & $\mathrm{Y}$ & $\mathrm{Y}$ & $\mathrm{Y}$ & $\mathrm{Y}$ & $\mathrm{Y}$ & $\mathrm{Y}$ & $\mathrm{Y}$ & $\mathrm{Y}$ & $\mathrm{Y}$ & $\mathrm{Y}$ & $\mathrm{N}$ & 15 \\
\hline Ertan [20] & $\mathrm{Y}$ & $\mathrm{Y}$ & $\mathrm{N}$ & $\mathrm{Y}$ & $\mathrm{Y}$ & $\mathrm{N}$ & $\mathrm{Y}$ & $\mathrm{Y}$ & $\mathrm{Y}$ & $\mathrm{Y}$ & $\mathrm{Y}$ & $\mathrm{Y}$ & $\mathrm{Y}$ & $\mathrm{Y}$ & $\mathrm{Y}$ & $\mathrm{Y}$ & $\mathrm{Y}$ & $\mathrm{N}$ & 15 \\
\hline Boerma [24] & $\mathrm{Y}$ & $\mathrm{Y}$ & $\mathrm{N}$ & $\mathrm{Y}$ & $\mathrm{N}$ & $\mathrm{N}$ & $\mathrm{Y}$ & $\mathrm{Y}$ & $\mathrm{Y}$ & $\mathrm{Y}$ & $\mathrm{Y}$ & $\mathrm{Y}$ & $\mathrm{Y}$ & $\mathrm{Y}$ & $\mathrm{Y}$ & $\mathrm{Y}$ & $\mathrm{Y}$ & $\mathrm{N}$ & 14 \\
\hline Cohen [31] & $\mathrm{Y}$ & $\mathrm{Y}$ & $\mathrm{N}$ & $\mathrm{Y}$ & $\mathrm{N}$ & $\mathrm{N}$ & $\mathrm{Y}$ & $\mathrm{Y}$ & $\mathrm{Y}$ & $\mathrm{Y}$ & $\mathrm{Y}$ & $\mathrm{Y}$ & $\mathrm{Y}$ & $\mathrm{Y}$ & $\mathrm{Y}$ & $\mathrm{Y}$ & $\mathrm{Y}$ & $\mathrm{N}$ & 14 \\
\hline Coleman [29] & $\mathrm{Y}$ & $\mathrm{Y}$ & $\mathrm{N}$ & $\mathrm{Y}$ & $\mathrm{N}$ & $\mathrm{N}$ & $\mathrm{Y}$ & $\mathrm{Y}$ & $\mathrm{Y}$ & $\mathrm{Y}$ & $\mathrm{Y}$ & $\mathrm{Y}$ & $\mathrm{Y}$ & $\mathrm{N}$ & $\mathrm{Y}$ & $\mathrm{Y}$ & $\mathrm{Y}$ & $\mathrm{N}$ & 13 \\
\hline Lehman [30] & $\mathrm{Y}$ & $\mathrm{Y}$ & $\mathrm{N}$ & $\mathrm{Y}$ & $\mathrm{N}$ & $\mathrm{N}$ & $\mathrm{Y}$ & $\mathrm{Y}$ & $\mathrm{Y}$ & $\mathrm{Y}$ & $\mathrm{Y}$ & $\mathrm{Y}$ & $\mathrm{Y}$ & $\mathrm{N}$ & $\mathrm{Y}$ & $\mathrm{Y}$ & $\mathrm{Y}$ & $\mathrm{N}$ & 13 \\
\hline Siegel [23] & $\mathrm{Y}$ & $\mathrm{Y}$ & $\mathrm{N}$ & $\mathrm{Y}$ & $\mathrm{N}$ & $\mathrm{N}$ & $\mathrm{Y}$ & $\mathrm{Y}$ & $\mathrm{Y}$ & $\mathrm{N}$ & $\mathrm{N}$ & $\mathrm{N}$ & $\mathrm{Y}$ & $\mathrm{Y}$ & $\mathrm{Y}$ & $\mathrm{Y}$ & $\mathrm{Y}$ & $\mathrm{N}$ & 11 \\
\hline Satterfield [19] & $\mathrm{Y}$ & $\mathrm{Y}$ & $\mathrm{N}$ & $\mathrm{Y}$ & $\mathrm{N}$ & $\mathrm{N}$ & $\mathrm{Y}$ & $\mathrm{Y}$ & $\mathrm{Y}$ & $\mathrm{Y}$ & $\mathrm{Y}$ & $\mathrm{Y}$ & $\mathrm{Y}$ & $\mathrm{N}$ & $\mathrm{Y}$ & $\mathrm{Y}$ & $\mathrm{Y}$ & $\mathrm{N}$ & 13 \\
\hline McCarthy [17] & $\mathrm{Y}$ & $\mathrm{Y}$ & $\mathrm{N}$ & $\mathrm{Y}$ & $\mathrm{N}$ & $\mathrm{N}$ & $\mathrm{Y}$ & $\mathrm{Y}$ & $\mathrm{Y}$ & $\mathrm{Y}$ & $\mathrm{Y}$ & $\mathrm{Y}$ & $\mathrm{Y}$ & $\mathrm{Y}$ & $\mathrm{Y}$ & $\mathrm{Y}$ & $\mathrm{Y}$ & $\mathrm{N}$ & 14 \\
\hline Jacob [14] & $\mathrm{Y}$ & Y & $\mathrm{N}$ & $\mathrm{Y}$ & $\mathrm{N}$ & $\mathrm{N}$ & $\mathrm{Y}$ & $\mathrm{Y}$ & $\mathrm{Y}$ & $\mathrm{Y}$ & $\mathrm{Y}$ & $\mathrm{Y}$ & $\mathrm{Y}$ & $\mathrm{Y}$ & $\mathrm{Y}$ & $\mathrm{Y}$ & $\mathrm{Y}$ & $\mathrm{N}$ & 14 \\
\hline Kozarek [16] & $\mathrm{Y}$ & $\mathrm{Y}$ & $\mathrm{N}$ & $\mathrm{Y}$ & $\mathrm{N}$ & $\mathrm{N}$ & $\mathrm{Y}$ & $\mathrm{Y}$ & $\mathrm{Y}$ & $\mathrm{Y}$ & $\mathrm{Y}$ & $\mathrm{Y}$ & $\mathrm{Y}$ & $\mathrm{N}$ & $\mathrm{Y}$ & $\mathrm{Y}$ & $\mathrm{Y}$ & $\mathrm{N}$ & 13 \\
\hline Lans [21] & $\mathrm{Y}$ & $\mathrm{Y}$ & $\mathrm{N}$ & $\mathrm{Y}$ & $\mathrm{Y}$ & $\mathrm{N}$ & $\mathrm{Y}$ & $\mathrm{Y}$ & $\mathrm{Y}$ & $\mathrm{Y}$ & $\mathrm{Y}$ & $\mathrm{Y}$ & $\mathrm{Y}$ & $\mathrm{N}$ & $\mathrm{Y}$ & $\mathrm{Y}$ & $\mathrm{Y}$ & $\mathrm{N}$ & 14 \\
\hline
\end{tabular}


concluded that the assumptions of the fixed effects model had been violated and used the random effects model to calculate pooled effects for each outcome and subgroup [12]. The results of heterogeneity testing for each measured outcome are noted in Table 1.

\section{Primary outcome: endoscopic therapy success rates}

In the 23 studies included in the analysis, a total of 874 patients received endoscopic therapy for PDiv. Endotherapy was deemed "successful" by the investigators in 589 of those patients. The pooled success rate of endotherapy was calculated at $67.5 \%$ (95\% confidence interval [CI] 0.610-0.734; 2-sided $\mathrm{P}=0.0001$ ). A forest plot of pooled endotherapy success rates is shown in Fig. 3. We analyzed the pooled endotherapy success rates of 3 patient subgroups: RAP, CP and PP. In total, 401 patients from 17 studies were reported to present with RAP and endotherapy was successful, as per author definition, in 289 of these patients. The pooled success rate of endotherapy in patients with RAP was 76\% (95\%CI 0.712-0.803; 2-sided $\mathrm{P}=0.0001$ ). Patients presenting with $\mathrm{CP}$ and PP did not benefit from endotherapy to the same extent. In 283 patients with CP, reported in 14 studies, endotherapy was successful in 164 . The pooled success rate in CP patients was $52.4 \%$ (95\%CI 0.406 $0.640 ; 2$-sided $\mathrm{P}=0.692$ ) indicating an equivocal effect in this subset of patients. Fewer patients were treated with PP; of 131 patients PPfrom 10 studies, endotherapy was successful in 64. The pooled success rate in PP patients was $48 \%$ (95\%CI 0.371-0.590; 2 -sided $\mathrm{P}=0.723$ ). Fig. 4 shows a forest plot of endotherapy success rates in patients with RAP, CP or PP. Of 23 studies, 19 reported rates of post-ERCP pancreatitis. The pooled rate of post-ERCP pancreatitis was calculated at $10.1 \%$ (95\%CI 0.084-0.124; 2-sided $\mathrm{P}=0.0001$ ).

\section{Predictors of successful endoscopic therapy}

Seventeen studies that had complete data for all the covariates assessed were included in a meta-regression analysis. The optimal regression fixed effects model included the following covariates: percentage of male patients, mean follow up in months, and dorsal pancreatic duct stenting only. This model explained $16 \%$ of the between-study variance with an $\mathrm{R}^{2}$ value of 0.16 , P-value $=0.059$.

Dorsal duct stenting only (coefficient $=1.66$, standard error $[\mathrm{SE}]=0.47,2$ sided $\mathrm{P}=0.004$ ) and longer duration of follow up (coefficient $=0.017, \mathrm{SE}=0.005,2$ sided $\mathrm{P}=0.012$ ) were the only factors associated with better endotherapy success rates. There was a trend for higher success rate among male patients that did not reach statistical significance $(2$ sided $\mathrm{P}=0.074)$.

\section{Discussion}

The primary objective of our meta-analysis was to assess the efficacy of endoscopic therapy in the management of PDiv and obtain a more accurate estimate of the effect size. We found that endoscopic therapy was reported to be successful in PDiv with a pooled efficacy rate of $67.5 \%$. Although this rate is likely to be more accurate than those reported in individual studies, it is far from being conclusive in view of the suboptimal study design, lack of a uniform outcome definition, and variable

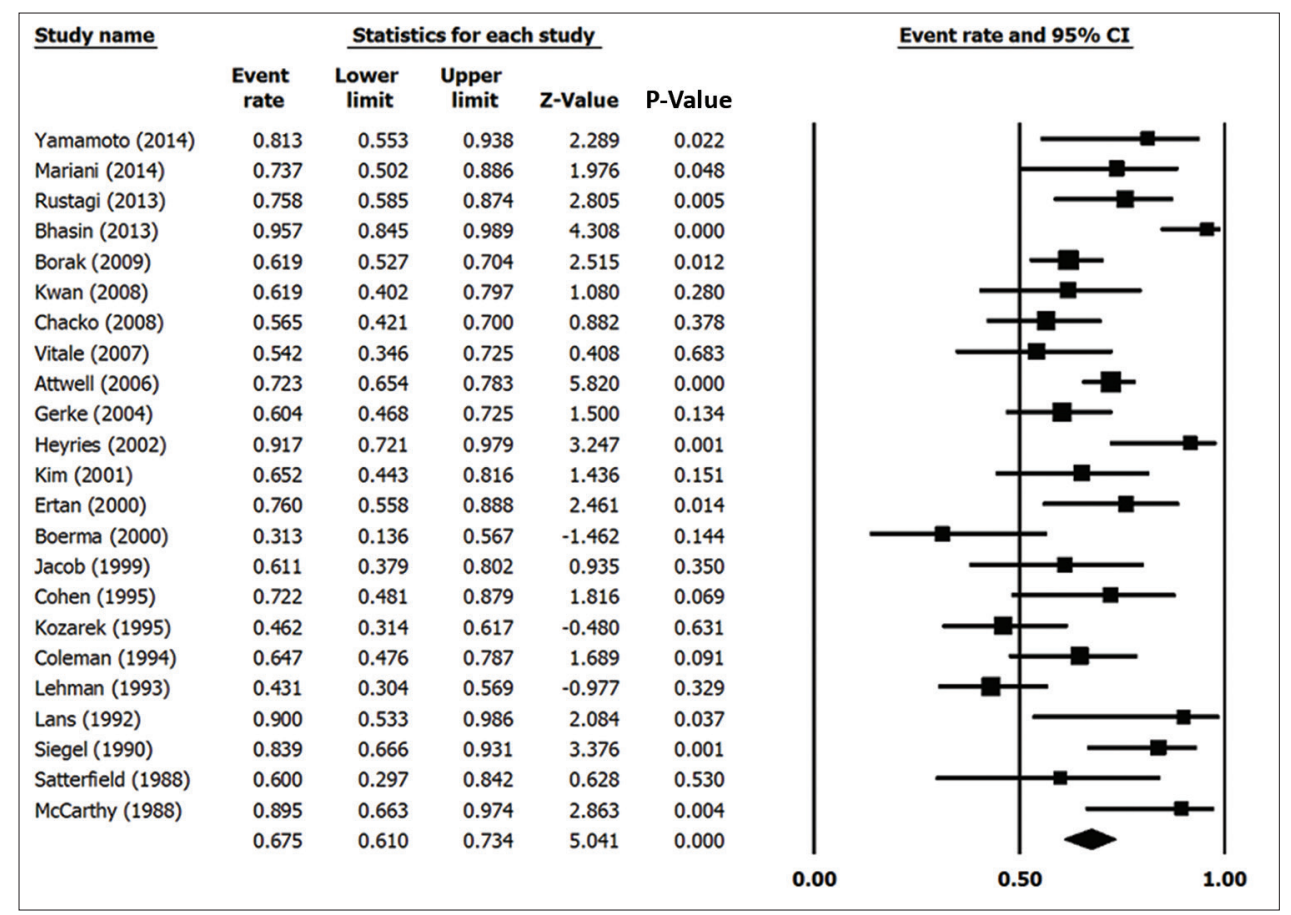

Figure 3 Forest plot of overall endotherapy success rate 


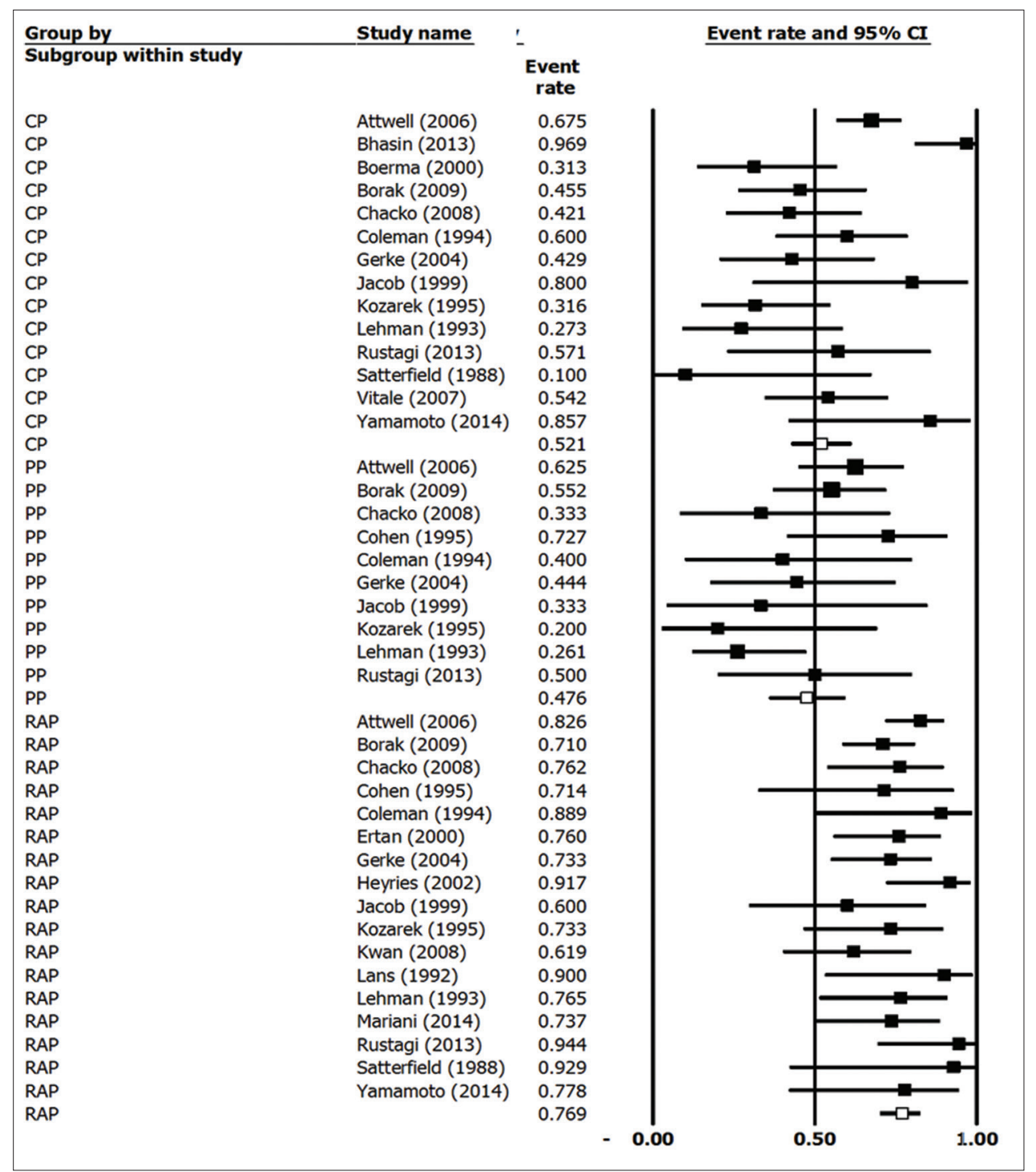

Figure 4 Forest plot of endotherapy success by clinical presentation

$R A P$, recurrent acute pancreatitis; $C P$, chronic pancreatitis; $P P$, pancreatic-type pain $P P$

follow-up durations among the studies analyzed. The definition of "successful therapy" varied quite significantly among studies. Some of the definitions used were: no recurrence of pancreatitis episodes after therapy [22,27], decreased number of pancreatitis episodes [28], improvement in patient-reported pain $[15,21,23,24,29,31]$ or no further pain reported [14,24,27], decreased use of analgesics [25], improvement in patientreported quality of life [26], no need for further therapy [32], no need for surgical therapy [33], decrease in the number of hospitalizations [18,30], decreased emergency room visits [17], and number of therapeutic ERCP sessions the patients required [34]. Several authors used a combination of these definitions [16,17,20,26,34,35]. These variable definitions of success make it hard to generalize conclusions.

Not all authors provided precise definitions of RAP, CP or PP in the studies. However, RAP was mostly defined as at least 2 prior documented episodes of pancreatitis without calcification of the pancreas; recurrent episodes of abdominal pain compatible with a pancreatic origin with an increase in amylase or lipase levels within a year. CP was defined as pancreatic pain coupled with typical radiographic or pancreatographic findings. The maximal therapeutic benefit was observed in patients who presented with RAP, with a pooled efficacy rate of $76 \%$. The therapeutic effect was equivocal in patients with CP and PP. The reason for this difference in response to endoscopic therapy is not fully understood. Some authors postulate that genetic factors predispose people with pancreatic disease to intermittent obstruction (leading to pancreatitis and sequelae $[36,37]$ ), which is alleviated by reducing transpapillary pressure with endotherapy in regard to RAP. In contrast, in CP and PP patients it has been suggested that the duct may have sustained irreversible damage that does not make it amenable to endoscopic drainage [18]. Others have postulated that the presence of PDiv is merely an incidental finding in this group 
of patients [2] and not the primary etiology behind their symptoms; thus, performing endotherapy would not improve their condition.

The post-ERCP pancreatitis pooled rate was $10 \%(95 \% \mathrm{CI}$ $0.084-0.124 ; \mathrm{P}=0.0001)$. Although reported rates vary in the literature, for comparison, in a large analysis of 21 prospective studies, involving 16,855 patients, ERCP-attributable complications occurred in $6.85 \%$ (95\%CI 6.46-7.24\%) of the procedures with a pancreatitis rate of $3.47 \%$ (95\%CI 3.19$3.75 \%$ ) [38]. In our analysis, the incidence of post-ERCP pancreatitis in patients with pancreatic disease undergoing endotherapy was higher compared to other indications, suggesting that efforts to minimize adverse outcomes should be considered. The exact reason for this is unclear, but the more interventional nature of PDiv endotherapy compared to standard diagnostic ERCP may have contributed to this observation. In addition, the varied types of endotherapy chronology, and other variables that were not reported or recorded in studies (such as the use of rectal indomethacin) make it difficult to extract conclusions.

We sought to identify potential predictors of successful endoscopic therapy through multivariate analysis. Other than clinical presentation, two variables were noted to be associated with improved outcomes: dorsal duct stenting only and longer follow-up duration. In addition, male patients tended to have better response rates, although the difference did not reach statistical significance. It is likely that dorsal duct stenting may decrease the risk of post-ERCP pancreatitis [41] and potentially allows for more effective drainage in some patients. However, it is important to note that only 2 out of the 17 studies in the regression analysis employed dorsal duct stenting only, without a sphincteroplasty or sphincterotomy, as the main endotherapy. Furthermore, those studies were some of the earlier ones, done in 1990 and 1992. The reason why better outcomes were associated with a longer follow-up duration is unclear. Potential explanations include the elimination of the placebo effect with longer duration, more endotherapy sessions and frequent contact with medical providers.

The major limitation of the current analysis is the absence of high-quality, well-designed studies. The studies available are by and large single-center uncontrolled retrospective case series with a high risk of selection and reporting bias. In addition, the definition of success varied widely and lacked validity and reliability in a significant number of studies; subjective measures, such as patient-rated improvement in pain, were frequently employed to determine success [39]. All of the above factors explain the substantial heterogeneity observed within and across studies. It is important to note that we only included fully published studies in the English language and funnel plots indicated the presence of at least potential publication bias (mostly studies with a positive effect).

In conclusion, endoscopic therapy for PDiv is probably effective in a subset of patients who present with RAP. The benefit is less clear in patients with CP and/or PP. The postERCP pancreatitis rate is higher than average and should be quoted at $10 \%$. The overall quality of the available data is poor, as a result of suboptimal study design and significant heterogeneity. High-quality prospective randomized trials,

\section{Summary Box}

\section{What is already known:}

- Pancreas divisum (PDiv) has been implicated in the pathogenesis of acute, recurrent and chronic pancreatitis as well as pancreatic type abdominal pain

- Endoscopic therapy is frequently used to treat PDiv, but reported efficacies vary widely between authors

- Endotherapy appears to be more effective in patients with recurrent acute pancreatitis

\section{What the new findings are:}

- The pooled efficacy of endoscopic therapy in PDiv in the featured studies was $67.5 \%$

- Dorsal duct stenting and longer duration of follow up were the only factors associated with improved endotherapy success rates

- The maximal therapeutic benefit was observed in patients who presented with recurrent pancreatitis, with a pooled efficacy rate of $76 \%$. The therapeutic effect was equivocal in patients with chronic pancreatitis or pancreatic type pain

with standardized, objective, valid and reliable outcome measures are needed to establish the exact role of endoscopic therapy in the management of PDiv.

\section{References}

1. Liao Z, Gao R, Wang W, et al. A systematic review on endoscopic detection rate, endotherapy, and surgery for pancreas divisum. Endoscopy 2009;41:439-444.

2. DiMagno MJ, Wamsteker EJ. Pancreas divisum. Curr Gastroenterol Rep 2011;13:150-156.

3. Delhaye M, Matos C, Arvanitakis M, Deviere J. Pancreatic ductal system obstruction and acute recurrent pancreatitis. World $J$ Gastroenterol 2008;14:1027-1033.

4. Klein SD, Affronti JP. Pancreas divisum, an evidence-based review: part I, pathophysiology. Gastrointest Endosc 2004;60:419-425.

5. Khalid A, Slivka A. Approach to idiopathic recurrent pancreatitis. Gastrointest Endosc Clin N Am 2003;13:695-716.

6. Hutton B, Salanti G, Caldwell DM, et al. The PRISMA extension statement for reporting of systematic reviews incorporating network meta-analyses of health care interventions: checklist and explanations. Ann Intern Med 2015;162:777-784.

7. Lutzak GD, Gluck M, Ross AS, Kozarek RA. Endoscopic minor papilla sphincterotomy in patients with santoriniceles reduces pain and improves quality of life. Dig Dis Sci 2013;58:2075-2081.

8. Wehrmann T, Schmitt T, Seifert H. Endoscopic botulinum toxin injection into the minor papilla for treatment of idiopathic recurrent pancreatitis in patients with pancreas divisum. Gastrointest Endosc 
1999;50:545-548.

9. Moga CGB, Schopflocher D, Harstall C. Development of a quality appraisal tool for case series studies using a modified Delphi technique. Edmonton AB: Institute of Health Economics 2012.

10. Higgins JP, Thompson SG. Quantifying heterogeneity in a metaanalysis. Stat Med 2002;21:1539-1558.

11. Higgins JP, Thompson SG, Deeks JJ, Altman DG. Measuring inconsistency in meta-analyses. BMJ 2003;327:557-560.

12. Huedo-Medina TB, Sánchez-Meca J, Marín-Martínez F, Botella J. Assessing heterogeneity in meta-analysis: Q statistic or I2 index? Psychol Methods 2006;1 1:193-206.

13. Hozo SP, Djulbegovic B, Hozo I. Estimating the mean and variance from the median, range, and the size of a sample. BMC Med Res Methodol 2005;5:13.

14. Jacob L, Geenen JE, Catalano MF, Johnson GK, Geenen DJ, Hogan WJ. Clinical presentation and short-term outcome of endoscopic therapy of patients with symptomatic incomplete pancreas divisum. Gastrointest Endosc 1999;49:53-57.

15. Kim MH, Lee SS, Kim CD, et al. Incomplete pancreas divisum: is it merely a normal anatomic variant without clinical implications? Endoscopy 2001;33:778-785.

16. Kozarek RA, Ball TJ, Patterson DJ, Brandabur JJ, Raltz SL. Endoscopic approach to pancreas divisum. Dig Dis Sci 1995;40:1974-1981.

17. McCarthy J, Geenen JE, Hogan WJ. Preliminary experience with endoscopic stent placement in benign pancreatic diseases. Gastrointest Endosc 1988;34:16-18.

18. Rustagi T, Golioto M. Diagnosis and therapy of pancreas divisum by ERCP: a single center experience. J Dig Dis 2013;14:93-99.

19. Satterfield ST, McCarthy JH, Geenen JE, et al. Clinical experience in 82 patients with pancreas divisum: preliminary results of manometry and endoscopic therapy. Pancreas 1988;3:248-253.

20. Ertan A. Long-term results after endoscopic pancreatic stent placement without pancreatic papillotomy in acute recurrent pancreatitis due to pancreas divisum. Gastrointest Endosc 2000;52:9-14.

21. Lans JI, Geenen JE, Johanson JF, Hogan WJ. Endoscopic therapy in patients with pancreas divisum and acute pancreatitis: a prospective, randomized, controlled clinical trial. Gastrointest Endosc 1992;38:430-434.

22. Mariani A, Di Leo M, Petrone MC, et al. Outcome of endotherapy for pancreas divisum in patients with acute recurrent pancreatitis. World J Gastroenterol 2014;20:17468-17475.

23. Siegel JH, Ben-Zvi JS, Pullano W, Cooperman A. Effectiveness of endoscopic drainage for pancreas divisum: endoscopic and surgical results in 31 patients. Endoscopy 1990;22:129-133.

24. Boerma D, Huibregtse K, Gulik TM, Rauws EA, Obertop H, Gouma DJ. Long-term outcome of endoscopic stent placement for chronic pancreatitis associated with pancreas divisum. Endoscopy 2000;32:452-456.

25. Heyries L, Barthet M, Delvasto C, Zamora C, Bernard JP, Sahel J. Long-term results of endoscopic management of pancreas divisum with recurrent acute pancreatitis. Gastrointest Endosc 2002;55:376-381.

26. Bhasin DK, Rana SS, Sidhu RS, et al. Clinical presentation and outcome of endoscopic therapy in patients with symptomatic chronic pancreatitis associated with pancreas divisum. JOP 2013;14:50-56.

27. Yamamoto N, Isayama H, Sasahira N, et al. Endoscopic minor papilla balloon dilation for the treatment of symptomatic pancreas divisum. Pancreas 2014;43:927-930.

28. Kwan V, Loh SM, Walsh PR, Williams SJ, Bourke MJ. Minor papilla sphincterotomy for pancreatitis due to pancreas divisum. ANZ J Surg 2008;78:257-261.

29. Coleman SD, Eisen GM, Troughton AB, Cotton PB. Endoscopic treatment in pancreas divisum. Am J Gastroenterol 1994;89:1152-1155.

30. Lehman GA, Sherman S, Nisi R, Hawes RH. Pancreas divisum: results of minor papilla sphincterotomy. Gastrointest Endosc 1993;39:1-8.

31. Cohen SA, Rutkovsky FD, Siegel JH, Kasmin FE. Endoscopic stenting and sphincterotomy of the minor papilla in symptomatic pancreas divisum: results and complications. Diagn Ther Endosc 1995;1:131-139.

32. Attwell A, Borak G, Hawes R, Cotton P, Romagnuolo J. Endoscopic pancreatic sphincterotomy for pancreas divisum by using a needleknife or standard pull-type technique: safety and reintervention rates. Gastrointest Endosc 2006;64:705-711.

33. Vitale GC, Vitale M, Vitale DS, Binford JC, Hill B. Long-term follow-up of endoscopic stenting in patients with chronic pancreatitis secondary to pancreas divisum. Surg Endosc 2007;21:2199-2202.

34. Borak GD, Romagnuolo J, Alsolaiman M, Holt EW, Cotton PB. Long-term clinical outcomes after endoscopic minor papilla therapy in symptomatic patients with pancreas divisum. Pancreas 2009;38:903-906.

35. Chacko LN, Chen YK, Shah RJ. Clinical outcomes and nonendoscopic interventions after minor papilla endotherapy in patients with symptomatic pancreas divisum. Gastrointest Endosc 2008;68:667-673.

36. Staritz M, Meyer zum Büschenfelde KH. Elevated pressure in the dorsal part of pancreas divisum: the cause of chronic pancreatitis? Pancreas 1988;3:108-110.

37. Muzaffar AR, Moyer MS, Dobbins J, Cahow CE, Gryboski JD, Shneider BL. Pancreas divisum in a family with hereditary pancreatitis. J Clin Gastroenterol 1996;22:16-20.

38. Andriulli A, Loperfido S, Napolitano G, et al. Incidence rates of post-ERCP complications: a systematic survey of prospective studies. Am J Gastroenterol 2007;102:1781-1788.

39. Moustgaard H, Bello S, Miller FG, Hróbjartsson A. Subjective and objective outcomes in randomized clinical trials: definitions differed in methods publications and were often absent from trial reports. J Clin Epidemiol 2014;67:1327-1334.

40. Gerke H, Byrne MF, Stiffler HL, et al. Outcome of endoscopic minor papillotomy in patients with symptomatic pancreas divisum. JOP 2004;5:122-131.

41. Singh P, Das A, Isenberg G, et al. Does prophylactic pancreatic stent placement reduce the risk of post-ERCP acute pancreatitis? A meta-analysis of controlled trials. Gastrointest Endosc 2004;60:544-550. 